\title{
Artigos Premiados e Editoriais Internacionais: a Busca do Crescimento Científico da Revista Brasileira de Cardiologia Invasiva
}

A edição de setembro de 2007 da Revista Brasileira de Cardiologia Invasiva $(\mathrm{RBCl})$ traz uma série de novidades, frutos da preocupação constante do Corpo Editorial e da Diretoria da SBHCl: a busca do crescimento e da qualificação científica da RBCl.

Esse número é encabeçado pelo artigo original "Evolução Clínica Tardia dos Stents Farmacológicos. Segurança e Eficácia até Cinco Anos do Registro DESIRE", de autoria da Dra. Amanda G.M.R. Sousa et al., que recebeu o prêmio de melhor tema livre apresentado no último Congresso da $\mathrm{SBHCl}$, em Brasília. Avalia a efetividade e segurança dos stents farmacológicos no maior registro brasileiro dedicado, com informações clínicas tardias obtidas na quase totalidade dos pacientes. Acompanham-no dois outros trabalhos premiados: "Avaliação do Custo do Implante Programado de Múltiplos Stents em Mais de uma Intervenção Percutânea em Pacientes com Doença Coronária Multiarterial", do Dr. George Ximenes et al., e "Síndrome Coronária Aguda sem Supradesnível de ST de Alto Risco: a Mortalidade IntraHospitalar é Proporcional ao Retardo Para a Intervenção", do Dr. Carlos Augusto Magalhães et al. A premiação para os melhores temas livres e para o melhor pôster, oferecida pela $\mathrm{SBHCl}$ a partir de 2007, foi instituída com a finalidade de incentivar a publicação nesta Revista dos artigos originais de maior impacto e repercussão na comunidade cardiológica intervencionista brasileira.

Outra novidade é a participação de convidados especiais na redação de alguns dos excelentes editoriais desse fascículo: o Dr. George Dangas, professor da Columbia University Medical Center e membro da Cardiovascular Research Foundation, em Nova York, autor do editorial intitulado "Reação Vascular Crônica Secundária à Sobreposição de Stents Farmacológicos" e o Dr. Gilson Feitosa, Professor Titular da Escola Bahiana de
Medicina e Saúde Pública, que opinou sobre o muito debatido estudo COURAGE. A participação destes convidados especiais, além de enriquecer o conteúdo da $\mathrm{RBCl}$, certamente atrairá ainda mais o interesse dos leitores.

Itens adicionais, que vão contribuir para o crescimento científico da $\mathrm{RBCl}$, dizem respeito à indexação e à divulgação internacional do nosso periódico. A partir desta edição, o conteúdo da Revista foi ampliado, com um aumento de $50 \%$ do número de artigos originais, revisões e relatos de caso, visando a atingir as requisições do Scientific Electronic Library Online - SciELO, biblioteca eletrônica que reúne uma coleção seleta de periódicos científicos brasileiros e nossa próxima meta para a indexação.

Dentro do contexto da divulgação internacional, medidas importantes foram tomadas. O Dr. Rogério Sarmento-Leite, Diretor de Comunicações da SBHCl, intermediou e conseguiu, com os dirigentes da Sociedade Latino-Americana de Cardiologia Intervencionista (SOLACI), Society for Cardiovascular Angiography and Interventions (SCAl) e Cardiovascular Research Foundation (TCT), a permissão para a colocação de um link da $\mathrm{RBCI}$ nos respectivos websites, com um texto convidando os leitores a visitarem e submeterem seus artigos a nossa Revista.

Gostaríamos de lembrar, ainda, que o website da $\mathrm{RBCl}$, inaugurado no último Congresso da $\mathrm{SBHCl}$, encontra-se em pleno funcionamento, disponibilizando aos leitores todos os artigos em arquivos "pdf" publicados a partir do segundo semestre de 2003, época em que a revista adquiriu seu formato atual.

Esperamos, com a implementação das medidas citadas, criar um círculo virtuoso que atraia ainda mais a submissão de artigos nacionais e internacionais para a $\mathrm{RBCl}$.

Áurea Jacob Chaves

Editora, Revista Brasileira de Cardiologia Invasiva 